\title{
Desain Sensor Kelembapan Relatif Udara Menggunakan Fiber Optik
}

\author{
Rangga Pradana Wahyudi ${ }^{1}$, Yoyok Heru Prasetyo, Mila Kusumawardani ${ }^{3}$ \\ ${ }^{1,2}$ Program Studi Jaringan Telekomunikasi Digital, \\ Jurusan Teknik Elektro, Politeknik Negeri Malang, Indonesia \\ ${ }^{3}$ Program Studi Teknik Telekomunikasi, \\ Jurusan Teknik Elektro, Politeknik Negeri Malang, Indonesia \\ 1anggapradana14@gmail.com, ${ }^{2}$ yoyok.heru@ polinema.ac.id, 3 mila.kusumawardani@ polinema.ac.id
}

\begin{abstract}
Air humidity is an important factor in human life, namely to maintain body health stability which will also affect work comfort. A sensor is needed to know the humidity in the room. A tool can be said to be a sensor if it has linearity and sensitivity, in this case optical fiber is suitable for sensors due to its natural ability to be resistant to electromagnetic interference, resistant to high temperatures, has high sensitivity and flexibility, and can be used for measurement and remote sensing. This study uses 2 singlemode SC-SC core patch cables connected to a fiber coupler that has been given a hole in the middle with a diameter of $1 \mathrm{~mm}$ and the ferulle spacing is $0.3 \mathrm{~mm}, 0.6 \mathrm{~mm}, 0.8 \mathrm{~mm}, 1 \mathrm{~mm}$. Optical light source is used to provide input with a value of $-7 \mathrm{dBm}$ and the output value will be read by the Optical power meter which will later be processed into power loss then compared with the value from the Hygrometer and will obtain a linear equation. The measurement results, it is found that the farther the distance between the ferules, the longer the range obtained. The longest range is obtained at a distance measurement of $1 \mathrm{~mm}$ with a power loss difference of $0.2 \mathrm{~dB}$ and the shortest range is obtained at a measurement of $0.3 \mathrm{~mm}$ with a power loss difference of $0.08 \mathrm{~dB}$.
\end{abstract}

Keywords: Optical fiber, fiber coupler, relative humidity, power loss, humidity sensor.

Abstrak - Kelembapan udara menjadi faktor penting dalam kehidupan manusia yaitu untuk menjaga kesetabilan kesehatan tubuhyang jugai akan berpengaruh kepada kenyamanan kerja. Diperlukan sensor untuk mengetahui kelembapan dalam ruangan. Alat bisa dikatakan sensor jika memiliki linearitas dan sensitivitas, dalam hal ini fiber optik cocok untuk sensor dikarenakan kemampuan alaminya yang tahan terhadap gangguan elektromagnetik, tahan terhadap suhu tinggi, memiliki sensitivitas dan fleksibelitas yang tinggi, dan dapat digunakan untuk pengukuran dan penginderaan jauh. Penelitian ini menggunakan 2 buah kabel patch core singlemode SC-SC yang dihubungkan dengan fiber coupler yang telah diberi lubang bagian tengahnya dengan diameter $1 \mathrm{~mm}$ dan diberi jarak antar ferullenya sebasar $0.3 \mathrm{~mm}, 0.6 \mathrm{~mm}, 0.8 \mathrm{~mm}, 1 \mathrm{~mm}$. Optical light source digunakan untuk memberikan masukan dengan nilai $-7 \mathrm{dBm}$ dan nilai keluaran akan dibaca oleh Optical power meter yang nantinya akan diolah menjadi loss daya kemudian dibandingkan dengan nilai kelembapan relatif dari Hygrometer dan akan diperoleh persamaan linearnya. Hasil pengukuran didapatkan semakin jauh jarak antar ferulle maka range yang didapat juga akan semakin panjang. Range terpanjang didapat pada pengukuran jarak $1 \mathrm{~mm}$ dengan selisih loss daya sebesar $0.2 \mathrm{~dB}$ dan range terpendek didapat pada pengukuran $0.3 \mathrm{~mm}$ dengan selisih loss daya sebesar $0.08 \mathrm{~dB}$.

Kata kunci- Fiber optik, fiber coupler, kelembapan relatif, loss daya, sensor kelembapan.

\section{PENDAHULUAN}

Kelembapan merupakan sesuatu yang sangat umum dan terus berubah sesuai keadaan lingkungan, pengukuran dan pengendalian kelembapan yang diperlukan dalam berbagai area seperti ruangan ber-AC, pemantauan kesehatan struktural, jasa meteorologi, industri pengolahan kimia dan makanan, kertas dan produksi tekstil, proses pembuatan semikonduktor [1].

Kelembapan udara menjadi faktor penting dalam kehidupan manusia yaitu untuk menjaga kesetabilan kesehatan tubuh, sehingga ini akan berpengaruh juga kepada kenyamanan kerja[2]. Menurut Kepmenkes no. 1405 tahun 2002 yang menjelaskan bahwa batas kelembapan ruang industri adalah 40\%-60\%. Karena ketika berada pada kelembapan yang tidak sesuai maka akan menurunkan konsentrasi dan mempercepat kelelahan[3].

Industri pemindangan adalah usaha pengolahan dan pengawetan ikan dengan melakukan proses perebusan untuk memasak dan mengasinkan ikan. Proses perebusan memerlukan waktu berkisar 3-6 jam dengan suhu $115^{\circ} \mathrm{C}$ dan menghasilkan tekanan udara 1.1 atmosfer, maka dari itu semakin tinggi tekanan udara maka semakin tinggi juga nilai kelembapan relatifnya[4]. Hal tersebut yang mengharuskan para karyawan menyesuaikan dengan keadaan lingkungan sehingga diperlukan alat untuk mengukur kelembapan lingkungan tersebut.

Alat ukur kelembapan saat ini hanya dapat mengukur kelembapan dengan suhu paling tinggi $85^{\circ} \mathrm{C}$. Sebelumnya sudah ada penelitian tentang ketahanan sensor menggunakan fiber optik hingga suhu $361^{\circ} \mathrm{C}$ namun masih memiliki kelemahan yaitu desain yang rumit dan belum mampu untuk mengukur kelembapan, selain itu harganya juga relatif mahal[5].

Sensor kelembapan berbasis fiber optik telah dikembangkan karena memiliki beberapa keunggulan diantaranya ketahanan terhadap gangguan elektromagnetik dan juga bentuk fisik yang kecil. Selain itu sensitivitas dari sensor kelembapan fiber optik juga tinggi [6]. 
Sensor kelembapan menggunakan serat optik sebagai pandu gelombang mempunyai beberapa kelebihan seperti daya tahan, desain miniatur, kemungkinan dapat bekerja di lingkungan yang mudah terbakar pada suhu dan rentang tekanan yang tinggi, dan kekekalan elektromagnetik [7, 8].

Berdasarkan hal-hal yang telah dikemukakan maka sensor fiber optik menggunakan fiber coupler memungkinkan untuk dibuat. Dengan konsep ketika ada partikel uap air yang melalui celah-celah fiber coupler, cahaya akan tetap terkirim dikarenakan cahaya mampu merambat melalui partikel kelembapan. Namun akan terjadi pembiasan sinar sehingga cahaya tidak terkirim sempurna dan mengakibatkan loss pada kabel fiber optik tersebut. Hasil loss atau redaman nanti akan diukur pada OPM dan dibandingkan dengan Hygrometer untuk mengkalibrasi sensor dan menentukan apakah layak fiber optik dengan desain ini digunakan untuk sensor kelembapan. Jika memiliki tingkat kesalahan yang kecil maka dapat diimplementasikan dengan kelebihan desain alat yang mudah dan murah juga dibantu dengan refrensi yang menjadi acuan[9].

Fiber optik adalah sebuah media transimisi berbahan kaca yang dapat mentransmisikan cahaya sehingga memiliki kelebihan dan kehandalan jika dibanding dengan media transmisi lain seperti kabel coaxial, kabel tembaga, maupun stripline. Serat optik memiliki 3 struktur utama, yaitu coating, cladding, dan core. Coating berfungsi untuk melindungi fisik dari cladding dan core, selain sebagai pelindung coating juga berfungsi sebagai pengkode warna. Cladding berfungsi sebagai pemandu dan cermin dari gelombang cahaya sehingga akan merefleksikan cahaya kembali ke core. Cladding terbuat dari bahan kaca, silica, ataupun plastik yang memiliki kualitas tinggi dan tentunya bebas dari air. Cladding memiliki indeks bias yang lebih kecil dari core. Core berfungsi sebagai saluran utama pentransmisi cahaya. Core terbuat dari bahan yang hampir sama dengan cladding yaitu kaca, silica, dan plastik. Core memiliki indeks bias yang lebih besar daripada cladding sehingga memungkinkan untuk terjadi pembiasan dalam total atau biasa disebut total internal reflection[10]. Penyerapan cahaya yang disebabkan oleh perubahan indeks bias cladding berpengaruh terhadap besarnya intensitas cahaya yang di transmisikan secara tidak langsung akibat perubahan kelembapan [11].

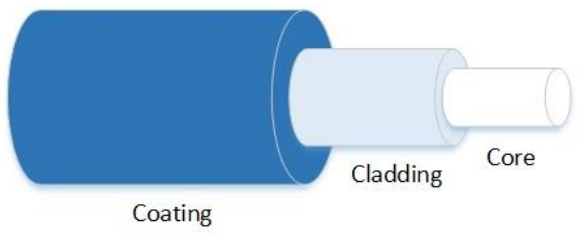

Gambar 1. Struktur fiber optik

Strukur utama dari sensor fiber optik adalah adanya sumber cahaya (LED), serat optik, elemen modulator, detektor cahaya, dan proses elektronik (Optical Spectrum Analyzer) yang berada dalam suatu sistem. Banyak keuntungan dirasakan ketika fiber optik digunakan sebagai sensor, sehingga penelitian semakin sering dikembangkan untuk meningkatkan jenis dari sensor tersebut[12]. Sistem sensor serat optik pada mekanismenya memodulasi gelombang cahaya dari suatu sumber seperti LED, laser dioda atau yang lainnya [13]. Sumber cahaya yang di pancarkan pada salah satu ujung serat optik menuju daerah transduser atau modulasi cahaya, kemudian di teruskan ke ujung lain serat optik dimana terdapat detektor cahaya. Keluaran dari detektor akan ditampilkan melalui penampil elektronik seperti LCD atau PC [14]. Sensor fiber optik dapat dikelompokkan berdasarkan dua kategori;

1. Berdasarkan lokasi sensor

Pembagian jenis sensor berdasarkan pembagian lokasi sensor dapat dibagi menjadi dua macam, yaitu: a. Intrinsik sensor

Fiber optik sebagai sensor intrinsik terjadi ketika satu atau lebih sifat fisik dari yang dialami fiber optik berubah. Gangguan yang terjadi menyebabkan perubahan karakteristik cahaya yang terjadi di dalam serat.

b. Ekstrinsik sensor

Sensor fiber optik pada jenis ini biasa digunakan untuk membawa cahaya dari atau menuju alat optik eksternal dimana pengukuran diambil. Pada kasus ini, serat optik bekerja jika mendapat cahaya dari daerah pengukuran.

2. Prinsip operasi sensor

Berdasarkan prinsip kerja dari proses modulasi atau demodulasi, sensor fiber optik dapat diklasifikasikan berdasarkan intensitas, phase, frekuensi atau polarisasi sensor. Semua parameter merupakan subjek untuk merubah gangguan eksternal. Sehingga, dengan mendeteksi parameter tersebut dan perubahan, maka gangguan dari luar dapat diukur. Sensor fiber optik dapat dikelompokkan berdasarkan tiga klasifikasi, yaitu;

a. Sensor fiber optik berdasarkan intensitas

Sensor fiber optik berdasarkan Intensitas dihubungkan dengan beberapa sinyal yang hilang. Alat ini dibuat dengan menggunakan perlengkapan untuk mengubah sesuatu besaran menjadi suatu besaran yang diukur bahwa fiber mengalami bending dan menyebabkan atenuasi sinyal. Cara lain untuk melakukan atenuasi pada sinyal yaitu dengan melakukan proses absorpsi atau scattering. Dengan mengamati perubahan intensitas, perubahan intensitas dapat terjadi akibat mikrobending fiber optik. Pendeteksian mikro bending dapat menggunakan OTDR (Optical Time Domain Reflectometer) sehingga dapat diketahui posisi terjadinya bending pada fiber optik.

b. Sensor fiber optik berdasarkan modulasi panjang gelombang

Sensor modulasi panjang gelombang menggunakan perubahan panjang gelombang atau cahaya untuk dideteksi. Contoh dari sensor modulasi panjang gelombang yaitu; Sensor Fluorescens, sensor benda hitam, dan brag gratting.

c. Sensor Fiber optik berdasarkan modulasi phase

Sensor ini menggunakan phasa yang berubah untuk mendeteksi cahaya. Perubahan phasa dideteksi secara interferometer dan methode yang digunakan untuk pendeteksian secara interferometer ini yaitu; MachZehnder, Michelson, Fabry-Perot, Sagnac, polarimetric, and grating interferometers. 
Pembiasan cahaya terjadi jika cahaya berjalan melewati batas antar dua medium yang berbeda seperti kaca atau air sehingga sebagian cahaya terlihat dibelokan. Ketika cahaya berjalan pada serat optik yang berbahan dasar transparan dan memiliki perbedaan indeks bias maka akan ada dua kemungkinan yakni sebagian cahaya akan dipantulkan atau akan diteruskan ke material transparan kedua. Pembelokan cahaya yang terjadi diakibatkan oleh perbedaan kecepatan cahaya dalam suatu bahan yang memiliki indeks bias yang berbeda[15].

\section{METODE PENELITIAN}

\section{A. Desain Pembuatan Alat}

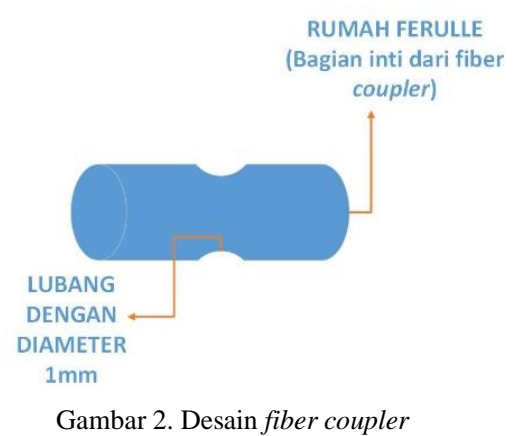

Tahap-tahap pembuatan alat sebagai berikut:

1. Siapkan fiber coupler SC-SC yang terbuat dari plastik.

2. Rumah ferrule yang berada di dalam fiber coupler dilepas dengan cara dicongkel secara perlahan, jangan sampai melukai rumah ferrulenya.

3. Siapkan mata bor khusus keramik dengan diameter $1 \mathrm{~mm}$ beserta bornya.

4. Berilah tanda pada bagian tengah rumah ferulle untuk menandai bagian yang akan dibor, usahakan tandanya searah sumbu $\mathrm{x}$ atau $\mathrm{y}$ dan harus lurus.

5. Bor pada bagian rumah ferulle yang telah ditandai secara perlahan.

6. Pastikan rumah ferrule bersih dan memiliki lubang bor yang lurus.

7. Alat dapat di uji coba dan ditunjukkan pada gambar 3.

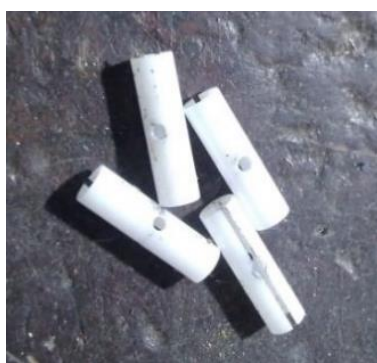

Gambar 3. Implementasi desain fiber coupler

\section{B. Rancangan Pengukuran Kabel Fiber Optik}

Pada penelitian ini perancangan pengukuran akan dilakukan pada dua tahap dan akan digambarkan dalam blok diagram. Urutan proses pengukurannya adalah pengukuran desain tanpa medium kelembapan, dan pengukuran desain menggunakan medium kelembapan terkontrol.

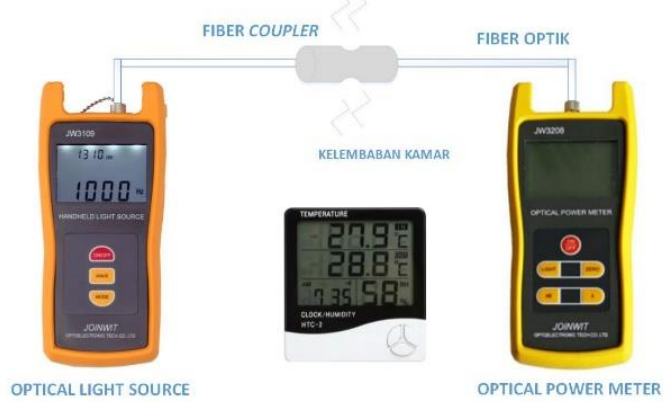

Gambar 4. Rancangan pengukuran dengan menggunakan kelembapan kamar

Pada pengukuran ini menggunakan dua kabel berjenis singlemode yang dirangkai seperti gambar 4. Pengukuran ini menggunakan desain fiber coupler untuk mengukur kelembapan udara. Antar ferulle diberi jarak 0.3mm, 0.6mm, $0.8 \mathrm{~mm}$, dan $1 \mathrm{~mm}$ untuk mengetahui batas bawah kelembapan dan untuk mengetahui rugi daya akibat jarak antar ujung ferulle. Untuk mengetahui rugi daya akibat jarak adalah dengan cara memberikan daya masukan dari OLS sebesar $-7 \mathrm{dBm}$ lalu dikirimkan melalui kabel fiber optik dan melewati fiber coupler untuk diukur oleh OPM nilai rugi-rugi dayanya.

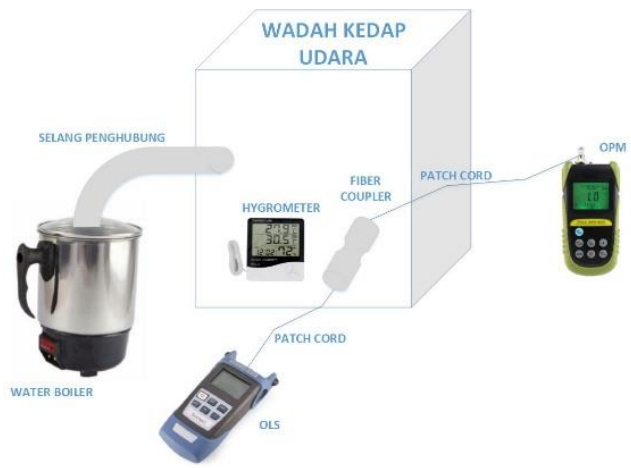

Gambar 5. Rancangan pengukuran dengan menggunakan kelembapan terkontrol

Pada pengukuran kali ini menggunakan fiber optik berjenis singlemode dengan rangkaian seperti pada gambar 6 . Pengukuran ini sudah menggunakan desain fiber coupler untuk mengukur kelembapan udara. Pada fiber coupler untuk antar ferulle diberi jarak $0.3 \mathrm{~mm}, 0.6 \mathrm{~mm}, 0.8 \mathrm{~mm}$, dan $1 \mathrm{~mm}$. Dengan batas bawah yang telah ditentukan pada gambar 4 maka untuk selanjutnya kelembapan udara akan dinaikan menggunakan water boiler dan diukur menggunakan Hygrometer. Kenaikan kelembapan pada hygrometer harus dipastikan stabil dan tidak berubah angkanya dalam kurun waktu 10 menit. Ketika sudah stabil maka bisa diasumsikan lubang pada fiber coupler sudah terisi dengan partikel kelembapan dan nilai pada OPM bisa diambil sehingga peningkatan hasil rugi-rugi dan kelembapan akan dibandingkan untuk setiap prosentase yang stabil dan dicocokan dengan teori. 


\section{Penentuan Prosedur Penelitian}

Pengukuran dengan menggunakan kelembapan kamar dilakukan untuk menentukan titik bawah pengukuran kelembapan dan belum diberi perlakuan apapun. Daya masukan yang diberikan oleh OLS sebesar $-7 \mathrm{dBm}$ dan akan dihitung hasil redamannya oleh OPM.

1. Mempersiapkan alat dan bahan yang akan digunakan dalam penelitian.

2. Alat dan bahan yang telah disiapkan dirangkai seperti yang tertera pada gambar 6 .

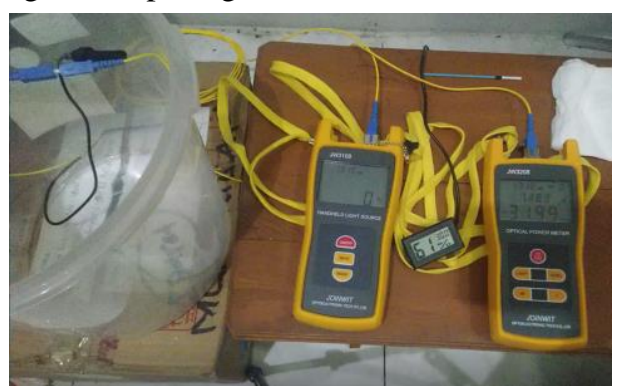

Gambar 6. Rangkaian pengukuran dengan menggunakan kelembapan kamar

3. Hidupkan OLS dan OPM dan atur panjang gelombang pada $1310 \mathrm{~nm}$.

4. Tunggu hingga hygrometer menunjukan nilai yang stabil, tunggu hingga kesetabilanya lebih dari 10 menit. Jika nilai pada hygrometer sudah stabil maka nilai redaman pada OPM bisa diambil.

5. Ulangi langkah 1 sampai 4 untuk setiap jarak antar ferulle $0.3 \mathrm{~mm}, 0.6 \mathrm{~mm}, 0.8 \mathrm{~mm}$, dan $1 \mathrm{~mm}$.

6. Untuk memberi jarak antar ferullenya menggunakan jarum yang dimasukan ke dalam lubang fiber coupler.

Pengukuran dengan menggunakan kelembapan relatif udara terkontrol dilakukan untuk menentukan hubungan antara kelembapan dan loss daya. Daya masukan yang diberikan oleh OLS sebesar $-7 \mathrm{dBm}$ dan akan dihitung hasil redamannya oleh OPM.

1. Mempersiapkan alat dan bahan yang akan digunakan dalam penelitian.

2. Alat dan bahan yang telah disiapkan dirangkai seperti yang tertera pada gambar 7 .

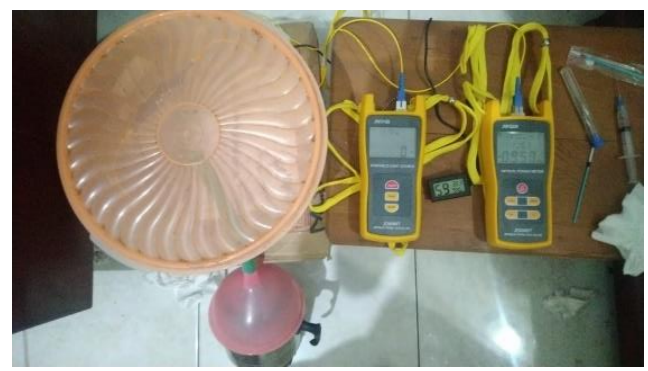

Gambar 7. Rangkaian pengukuran desain menggunakan medium kelembapan udara terkontro

3. Hidupkan OLS dan OPM dan atur panjang gelombang pada $1310 \mathrm{~nm}$.

4. Tutup wadah toples dengan rapat dan masukan uap water boiler menggunakan selang kedalam wadah toples. Setelah dirasa cukup maka cabut selang dan tutup kembali lubang selang dengan selotip.

5. Tunggu hingga hygrometer menunjukan nilai yang stabil, tunggu hingga kesetabilanya lebih dari 10 menit. Jika nilai pada hygrometer sudah stabil maka nilai redaman pada OPM bisa diambil.

6. Ulangi langkah 1 sampai 4 untuk setiap jarak antar ferulle $0.3 \mathrm{~mm}, 0.6 \mathrm{~mm}, 0.8 \mathrm{~mm}$, dan $1 \mathrm{~mm}$.

7. Untuk memberi jarak antar ferullenya menggunakan jarum yang dimasukan ke dalam lubang fiber coupler.

\section{HASIL DAN PEMBAHASAN}

A. Hasil Pengukuran loss daya fiber optik dengan jarak antar ferrule $0.3 \mathrm{~mm}$

TABEL I

HASIL PENGUKURAN LOSS DAYA PADA JARAK ANTAR FERULLE

\begin{tabular}{rrrrr}
\hline $\begin{array}{c}\text { Jarak } \\
\text { antar } \\
\text { ferulle }\end{array}$ & $\begin{array}{c}\text { Relative } \\
\text { Humidity } \\
(\%)\end{array}$ & $\begin{array}{c}\mathbf{X}^{\mathbf{2}} \text { (Hasil kuadrat } \\
\text { dari Relative } \\
\text { Humidity) }\end{array}$ & $\begin{array}{c}\text { Daya yang } \\
\text { terukur pada } \\
\text { OPM (dBm) }\end{array}$ & $\begin{array}{c}\text { Loss } \\
\text { daya } \\
(\mathbf{d B})(\mathbf{Y})\end{array}$ \\
\hline $0,3 \mathrm{~mm}$ & 64,4 & 0,41429 & $-18,4$ & 11,4 \\
& 66,4 & 0,44071 & $-18,4$ & 11,4 \\
& 68,4 & 0,4678 & $-18,4$ & 11,4 \\
& 71,4 & 0,51037 & $-18,41$ & 11,41 \\
& 72,4 & 0,5247 & $-18,41$ & 11,41 \\
& 74,5 & 0,55475 & $-18,42$ & 11,42 \\
& 76,5 & 0,58537 & $-18,43$ & 11,43 \\
& 83,6 & 0,69961 & $-18,44$ & 11,44 \\
& 86,7 & 0,75182 & $-18,46$ & 11,46 \\
87,7 & 0,76983 & $-18,48$ & 11,48 \\
\hline
\end{tabular}

Dari tabel 1 diperoleh titik-titik koordinat yang nantinya dicari persamaan liniernya sehingga didapatkan persamaan baru untuk menghitung loss daya.

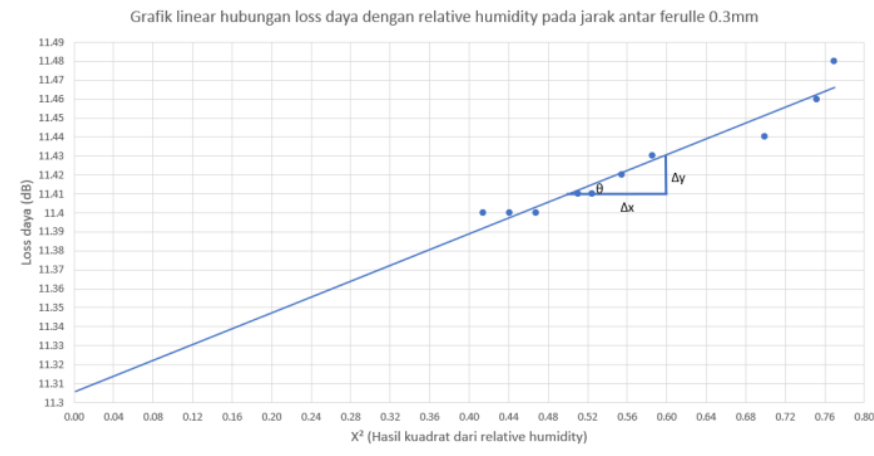

Gambar 8. Grafik linier hubungan antara loss daya dan RH dengan jarak antar ferulle $0.3 \mathrm{~mm}$

Untuk mencari persamaan dari grafik linier tersebut maka dapat dicari dengan cara:

$$
\begin{aligned}
& \mathrm{y}=\mathrm{mH}+\mathrm{c} \\
& \mathrm{m}=\tan \alpha=\Delta \mathrm{Y} / \Delta \mathrm{H} \\
& \begin{aligned}
\Delta \mathrm{Y} / \Delta \mathrm{H} & =(\mathrm{Y} 2-\mathrm{Y} 1) /(\mathrm{H} 2-\mathrm{H} 1) \\
& =(11.43-11.41) /(0.6-0.5) \\
& =0.2
\end{aligned}
\end{aligned}
$$

Jadi persamaan liniernya adalah $\mathrm{y}=0.2 \mathrm{H}+11.306$ dengan nilai error rate $0.05 \%$. 
Jurnal Jaringan Telekomunikasi, E-ISSN: 2654-6531, P-ISSN: 2407-0807 Vol. 11, No. 4 (2021) 214-219

B. Hasil Pengukuran loss daya fiber optik dengan jarak antar ferrule $0.8 \mathrm{~mm}$.

TABEL II

HASIL PENGUKURAN LOSS DAYA PADA JARAK ANTAR FERULLE 0.8MM

\begin{tabular}{cccrr}
\hline $\begin{array}{c}\text { Jarak } \\
\text { antar } \\
\text { ferulle }\end{array}$ & $\begin{array}{c}\text { Relative } \\
\text { Humidity } \\
(\boldsymbol{\%})\end{array}$ & $\begin{array}{c}\mathbf{X}^{\mathbf{2}} \text { (Hasil kuadrat } \\
\text { dari Relative } \\
\text { Humidity) }\end{array}$ & $\begin{array}{c}\text { Daya yang } \\
\text { terukur pada } \\
\text { OPM (dBm) }\end{array}$ & $\begin{array}{c}\text { Loss } \\
\text { daya } \\
\text { (dB) }(\mathbf{Y})\end{array}$ \\
\hline $0,8 \mathrm{~mm}$ & 64,4 & 0,41426 & $-26,92$ & 19,92 \\
& 66,4 & 0,44077 & $-26,94$ & 19,94 \\
& 67,4 & 0,45403 & $-26,95$ & 19,95 \\
& 69,4 & 0,48192 & $-26,97$ & 19,97 \\
& 75,5 & 0,57008 & -27 & 20 \\
& 77,5 & 0,6014 & $-27,02$ & 20,02 \\
& 84,7 & 0,71665 & $-27,04$ & 20,04 \\
& 85,7 & 0,73406 & $-27,06$ & 20,06 \\
& 87,7 & 0,76943 & $-27,07$ & 20,07 \\
& 89,8 & 0,80573 & $-27,08$ & 20,08 \\
\hline
\end{tabular}

Dari tabel 2 diperoleh titik-titik koordinat yang nantinya dicari persamaan liniernya sehingga didapatkan persamaan baru untuk menghitung loss daya.

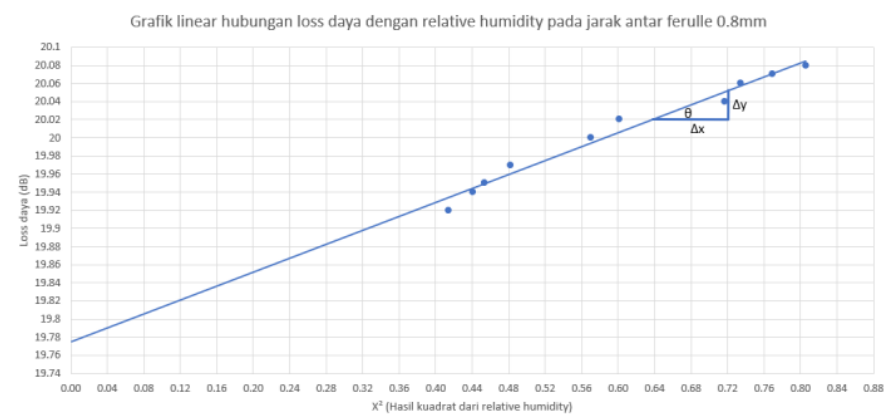

Gambar 9. Grafik linier hubungan antara loss daya dan RH dengan jarak antar ferulle $0.8 \mathrm{~mm}$

Untuk mencari persamaan dari grafik linier tersebut maka dapat dicari dengan cara:

$$
\begin{aligned}
& \mathrm{y}=\mathrm{mH}+\mathrm{c} \\
& \mathrm{m}=\tan \alpha=\Delta \mathrm{Y} / \Delta \mathrm{H} \\
& \begin{aligned}
\Delta \mathrm{Y} / \Delta \mathrm{H} & =(\mathrm{Y} 2-\mathrm{Y} 1) /(\mathrm{H} 2-\mathrm{H} 1) \\
& =(20.05-20.02) /(0.72-0.64) \\
& =0.375
\end{aligned}
\end{aligned}
$$

Jadi persamaan liniernya adalah $\mathrm{y}=0.375 \mathrm{H}+19.775$ dengan nilai error rate sebesar $0.04 \%$.

C. Hasil Pengukuran loss daya fiber optik dengan jarak antar ferrule $1 \mathrm{~mm}$.

TABEL III

HASIL PENGUKURAN LOSS DAYA PADA JARAK ANTAR FERULLE 1MM

\begin{tabular}{lcrrr}
\hline $\begin{array}{c}\text { Jarak } \\
\text { antar } \\
\text { ferulle }\end{array}$ & $\begin{array}{c}\text { Relative } \\
\text { Humidity } \\
(\%)\end{array}$ & $\begin{array}{c}\mathbf{X}^{\mathbf{2}} \text { (Hasil kuadrat } \\
\text { dari Relative } \\
\text { Humidity) }\end{array}$ & $\begin{array}{c}\text { Daya yang } \\
\text { terukur pada } \\
\text { OPM }(\mathbf{d B m})\end{array}$ & $\begin{array}{c}\text { Loss daya } \\
\text { (dB) }(\mathbf{Y})\end{array}$ \\
\hline $1 \mathrm{~mm}$ & 64,4 & 0,41437 & $-28,43$ & 21,43 \\
& 67,4 & 0,45419 & $-28,45$ & 21,45 \\
& 68,4 & 0,46787 & $-28,46$ & 21,46 \\
& 73,5 & 0,53964 & $-28,49$ & 21,49 \\
& 76,5 & 0,58551 & $-28,52$ & 21,52 \\
& 83,7 & 0,6999 & $-28,55$ & 21,55 \\
& 84,7 & 0,7171 & $-28,56$ & 21,56 \\
& 86,7 & 0,75191 & $-28,58$ & 21,58 \\
& 88,8 & 0,78785 & $-28,6$ & 21,6 \\
& 90,8 & 0,82446 & $-28,63$ & 21,63 \\
\hline
\end{tabular}

Dari tabel 3 diperoleh titik-titik koordinat yang nantinya dicari persamaan liniernya sehingga didapatkan persamaan baru untuk menghitung loss daya.

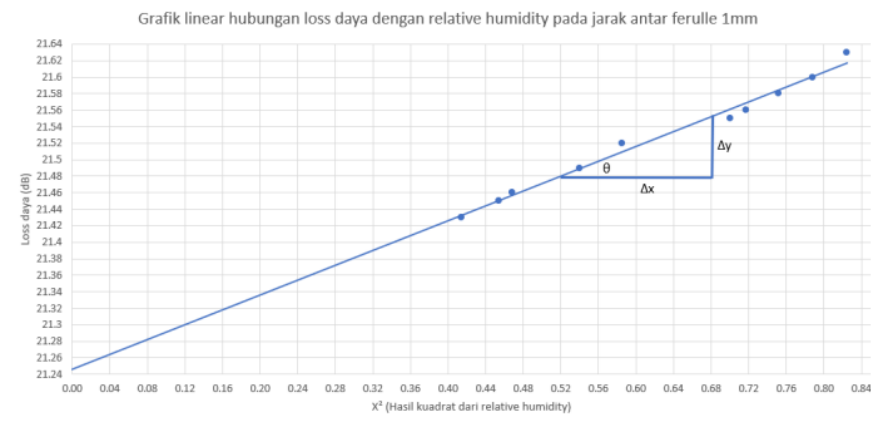

Gambar 10. Grafik linier hubungan antara loss daya dan RH dengan jarak antar ferulle $1 \mathrm{~mm}$

Untuk mencari persamaan dari grafik linier tersebut maka dapat dicari dengan cara:

$$
\begin{aligned}
& \mathrm{y}=\mathrm{mH}+\mathrm{c} \\
& \mathrm{m}=\tan \alpha=\Delta \mathrm{Y} / \Delta \mathrm{H} \\
& \begin{aligned}
\Delta \mathrm{Y} / \Delta \mathrm{H} & =(\mathrm{Y} 2-\mathrm{Y} 1) /(\mathrm{H} 2-\mathrm{H} 1) \\
& =(21.552-21.48) /(0.68-0.52) \\
& =0.45
\end{aligned}
\end{aligned}
$$

Jadi persamaan liniernya adalah $\mathrm{y}=0.45 \mathrm{H}+21.247$ dengan nilai error rate sebesar $0.03 \%$.

\section{KESIMPULAN}

1. Industri pemindangan adalah usaha pengolahan dan pengawetan ikan dengan melakukan proses perebusan untuk memasak dan mengasinkan ikan. Kelembapan dan suhu di area pemindangan sangatlah tinggi sehingga perlu alat pengukur kelembapan yang tahan akan suhu tinggi untuk mengukurnya. Sehingga dibuatlah alat yang dapat mengukur kelembapan pada suhu yang tinggi yaitu menggunakan fiber optik sebagai bahan utamanya.

2. Untuk mendesain sensor kelembapan relatif udara menggunakan fiber optik maka dibutuhkan fiber coupler yang telah dilubangi untuk memberi celah antar ferulle agar kelembapan relatif udara bisa masuk diantaranya. Jarak antar ferrule memiliki variasi $0.3 \mathrm{~mm}, 0.6 \mathrm{~mm}$, $0.8 \mathrm{~mm}$, dan $1 \mathrm{~mm}$ dengan diameter lubang fiber coupler $1 \mathrm{~mm}$. Untuk menambah performa dari sensor kelembapan relatif udara maka diperlukan juga media pentransmisi yang cocok seperti patch cord berjenis single mode yang memiliki kapasitas lebih besar dalam pentransmisian informasi dikarenakan bisa mempertahankan akurasi dari jumlah cahaya agar jarak tempuhnya menjadi besar. Ditambah dengan sifat alami dari fiber optik yang memiliki sensitivitas yang baik dan tahan terhadap suhu tinggi maka desain sensor fiber optik ini dapat diimplementasikan pada industri pemindangan ikan.

3. Untuk menentukan apakah terjadi perubahan loss daya yang diakibatkan adanya kelembapan relatif udara yang melewati fiber coupler maka perlu diberikan kelembapan terkontrol dengan cara memasukan fiber coupler ke dalam 
Jurnal Jaringan Telekomunikasi, E-ISSN: 2654-6531, P-ISSN: 2407-0807 Vol. 11, No. 4 (2021) 214-219

wadah kedap udara dengan masukan dari OLS sebesar $7 \mathrm{dBm}$ dengan nilai loss daya paling besar adalah $21.63 \mathrm{~dB}$ dengan jarak antar ferrule $1 \mathrm{~mm}$ dan nilai loss paling kecil adalah $11.4 \mathrm{~dB}$ dengan jarak antar ferulle $0.3 \mathrm{~mm}$. Jadi semakin jauh jarak antar ferullenya dan semakin banyak kelembapan udara relatif yang masuk pada celah fiber coupler sehingga memiliki range loss daya yang panjang. Untuk mendesain sensor kelembapan relatif udara dibutuhkan range yang panjang sehingga memiliki tingkat presisi yang baik bagi sensor.

4. Hasil nilai pengukuran hubungan antara loss daya dengan kelembapan didapatkan bentuk grafik mendekati parabolic sehingga didapatkan persamaan kuadratik. Untuk merubah ke dalam persamaan linear maka digunkanlah rumus $\mathrm{y}=\mathrm{mH}+\mathrm{c}$. Setiap jarak antar ferulle memiliki nilai persamaan yang berbeda beda. Dari perhitungan rumus persamaan didapatkan nilai range ter jauh pada jarak antar ferulle $1 \mathrm{~mm}$, dihitung dengan menggunakan persamaan linear maka didapat persamaan y $=0.45 \mathrm{H}+21.247$ dengan error sebesar $0.03 \%$. Semakin kecil error maka semakin baik untuk dijadikan desain sensor kelembapan udara relatif.

\section{REFERENSI}

[1] T.L Yeo, T. Sun and K.T.V. Grattan, "Fiber-optic sensor technologies for humidity and moisture measurement", Sens. Actuators, A., vol. 144, pp. 280 295, 2008.

[2] A. Simangunsong, "Kesehatan Lingkungan Kerja Home Industri Tembaga Kotagede Yogyakarta Nur," J. Huk. IUS QUIA IUSTUM, vol. 10, no. 24, pp. 164-189, 2003, doi: 10.20885/iustum.vol10.iss24.art14.

[3] A. Faramaretri et al., "Kenyamanan lingkungan kerja dan produktivitas kerja di unit sortasi budidaya jamur merang," vol. x, pp. 1-5, 2010.

[4] M. S. Budiman, Teknik Pemindangan. 2004.

[5] A. Gita Gumilang, Y. Heru Prasetyo Isnomo, and Waluyo, "Pengukuran Suhu Menggunakan Media Fiber Optik Berdasarkan Nilai Panjang Gelombang," J. JARTEL ISSN (PRINT) 2407-0807, ISSN(ONLINE) 2654-6531 Vol. 8, Nomor 1, 2019.

[6] Ichwan Abimanyu, "Pengaruh Pelapisan Silica Gel terhadap Sensitivitas Sensor Kelembapan Berbasis Fiber Optik Polimer", UNY, Yogyakarta, 2018.

[7] J.J. Ascorbe, J.M. Corres, F.J. Arregui, and I.R. Matias, "Recent Developments in Fiber Optics", Humudity Sensors, vol. 1, no. 4, pp. 893-901, 2017.

[8] C. Kelb, M. Korner, O. Prucker, J. Ruhe, E. Reitmeier, and B. Roth,"PDMAA Hydogel Coated U-Bend", Humudity Sensor Suited for Mass-Production Sensors, vol. 17, no. 4, pp. 517- 525, 2017.

[9] Y. H. P. Isnomo, M. N. Zakaria, M. Junus, M. A. Anshori, and A. Aisah, "Optical fiber temperature sensor design," IOP Conf. Ser. Mater. Sci. Eng., vol. 732, no. 1, 2020, doi: 10.1088/1757899X/732/1/012108.

[10] A. Hanafiah, "Teknologi Serat Optik,” J. Sist. Tek. Ind., vol. 7, no. 1, pp. 87-91, 2006.

[11] A. Maddu, K. Modjahidin, S. Sardy, H. Zain,'Pengembangan Probe Sensor Kelembapan Serat Optik dengan Cladding Gelatin”, Makara, vol. 10, no. 1, hlm. 45-50, 2006.

[12] D. Pratomo, "Pemanfaatan Prinsip Kerja Sensor Serat Optik Pergeseran Mikro untuk Medesain Alat Ukur Massa," 2011.

[13] K. Fidanboylu and H.S. Efendioglu, "Fiber Optic Sensors and Their Aplications",, 5th International Advanced Technologies Symposium, Karabuk, Turkey, pp. 13-15, 2009.

[14] Febrielviyanti, Harmadi, Dahyunir Dahlan, dan Yetria Rilda, "RAncang Bangun Sensor Kelembapan Udara menggunakan Plastic Optical Fiber (POF) dengan Cladding TiO2-SiO2 dan Data Transmisi", Jurnal Fisika dan Aplikasinya, Vol. 15, pp. 29-33, 2019.

[15] P. Indeks, B. Zat, and C. Melalui, "Pengukuran Indeks Bias Zat Cair Melalui Metode Pembiasan Menggunakan Plan Paralel," J. Fis. Unnes, vol. 3, no. 2, p. 80094, 2013, doi: 10.15294/jf.v3i2.3818. 